\title{
Patient Satisfaction in Tertiary Private Hospitals in Najran, Kingdom of Saudi Arabia
}

\author{
1Jordan H Llego, ${ }^{2}$ Mohammad O Al Shirah
}

\section{ABSTRACT}

Aim: This study is aimed to assess the level of satisfaction of patients in tertiary private hospitals in Najran, Kingdom of Saudi Arabia

Materials and methods: This study used descriptive crosssectional design through a survey questionnaire.

Results: A great majority (57\%) of respondents are male. Almost half $(46.7 \%)$ of the respondents are 26 to 35 years old, some $(30.3 \%)$ are more than 35 years old. The majority $(54.5 \%)$ of hospitalized patients are married. Some $(35.8 \%)$ of them reached the secondary level and some (31.5\%) completed college. A great majority (57.6\%) of the respondents' salary was below $5,000 \mathrm{SR}$. A great majority pay their hospitalization by themselves $(60.6 \%)$. Mean scores revealed: For facilities, the mean was 4.12 , standard deviation (SD) $=0.85$. For general services, the mean was $=4.13, S D=0.77$. The physician services scored mean $=4.06, S D=0.88$. The highest level of satisfaction according to mean is nursing services with mean $=4.22, \mathrm{SD}=0.80$ and the lowest among the variables is convenience with mean $=4.05, S D=0.84$. The overall level of patient satisfaction with the services they received indicated by the mean is $3.91, \mathrm{SD}=1.1$.

Conclusion: Researchers conclude that patients catered by the private tertiary hospitals in Najran Saudi Arabia are more of males, at middle adulthood, and are married who reached the secondary level and have an income of below 5,000 SR and have no health insurance. The level of satisfaction of patients in the private tertiary hospitals is satisfactory and that nursing service has the highest satisfaction level, which is very satisfactory.

Clinical significance: The findings of this study are beneficial to the success of the organization. A patient who is satisfied will spread his experience to other people. A satisfied patient will also equate to return of investment. Meeting satisfaction of patients will also decrease the risk of malpractice lawsuits.

Keywords: Malpractice lawsuits, Patient satisfaction, Tertiary private hospitals.

How to cite this article: Llego JH, Al Shirah MO. Patient Satisfaction in Tertiary Private Hospitals in Najran, Kingdom of Saudi Arabia. Int J Res Foundation Hosp Healthc Adm 2017;5(1):42-46.

\footnotetext{
1,2 Lecturer

1,2Department of Health Administration, Al-Ghad International College for Applied Medical Sciences, Najran, Kingdom of Saudi Arabia

Corresponding Author: Jordan H Llego, Lecturer, Department of Health Administration, Al-Ghad International College for Applied Medical Sciences, Najran, Kingdom of Saudi Arabia Phone: +966550153352, e-mail: llegojordan@gmail.com,
}

Source of support: Nil

Conflict of interest: None

\section{INTRODUCTION}

Patient satisfaction is how patients perceived the quality of service they are receiving. In health care, this is very important, because health care organizations deal more with people. Patient satisfaction is a serious question for health care providers. ${ }^{1}$ It is also an important and commonly used indicator for measuring the quality of health care. ${ }^{2}$

A satisfied patient can bring a number of advantages; some of these are as follows: Increase in patient loyalty, improved patient retention, patients complain less if there is an increase in price, stable income flow, increases the self-esteem of staffs, reduced malpractice cases, and increased professional and personal satisfaction. ${ }^{2}$ With this, it is really important that health care organizations should satisfy the needs of their patients. On the contrary, dissatisfied patients can lead to drop in patient loyalty; problems with this will push patients away and unhappy customers spread the word. ${ }^{3}$ Dissatisfied patients can really hurt a health care organization. Tertiary hospital or medical center caters to patients and provide subspecialty expertise, meaning that these hospitals are state of the art and should give quality service to its patients.

The primary goal of tertiary care hospitals is to provide best possible health care to the patients. In the modern era, it is the right of every patient to demand the best possible care in hospitals, and it is the duty of every staff member of the hospital to deliver his/her optimum efforts to the entire satisfaction of the patient, ${ }^{1}$ and its assessment will give an opportunity to find loopholes in services of the hospitals for future ratification. ${ }^{4}$

In the study of Ham et $\mathrm{al}_{1}^{5}$ wherein they studied predictors of patient satisfaction, they found that convenient check-in and check-out processes, nurse professional appearance, doctors' respect and courtesy for the patient, technician's friendly manner, and the presence of a comfortable waiting area are the strongest predictors of patient satisfaction. Positive reports are also seen in other studies like the study of Adekanye et al, ${ }^{6}$ where they studied a tertiary hospital in north central Nigeria and found that a great majority of their respondents were satisfied with the hospital services and met their expectation. 
Further, satisfaction was lowest in the revenue section and highest at the maternity section. In India, Shekhawat et $\mathrm{al}^{7}$ studied the level of satisfaction of inpatients in Mahatma Gandhi Medical College and Hospital, a tertiary hospital, and found that satisfaction was good regarding the quality of health care services. Areas where patient satisfaction was found to be lowest were patience shown by the nursing staff while communicating with patients and hospital ambiance in terms of peacefulness; both of these are important aspects of health care and there is an imperative need to address these problems effectively and urgently in order to improve the quality of care. With these data in mind, hospitals in Asia are delivering well to excellent care to its patients.

Although there are a lot of studies about the level of satisfaction of patients, it is rarely done in Najran, Saudi Arabia. This study may be the pioneer of its kind in this area. This study is of significance to the people in Najran for them to know the satisfactory level of private tertiary hospitals in the area; it is also beneficial to the hospitals so that they could look into things that they could and should improve. Further, this could also be beneficial to the Ministry of Health of Saudi Arabia as a monitoring tool and could be a data for their evaluation of private tertiary hospitals in Najran.

\section{MATERIALS AND METHODS}

\section{Study Design}

This study is aimed to assess the level of satisfaction of patients in tertiary private hospitals in Najran, Saudi Arabia. This study used descriptive cross-sectional design through a survey questionnaire.

\section{Respondents}

The respondents of this study are patients from three tertiary private hospitals in Najran, Saudi Arabia. Patients registered in these hospitals from Najran agreed to participate in the study; excluding out-patients, newly registered in-patients and are not hospitalized for the period of February to March 2017. The three hospitals have a total of 290-bed capacity using sample size calculator (2012), 165 inpatients are calculated to be the study sample based on calculation at a confidence level of $95 \%$. The study used purposive sampling.

Further, the researchers based the distribution of the respondents by the bed capacity of the hospitals. The bed capacities of the three hospitals are as follows: Hospital A -140 , hospital B - 100, and hospital C - 50. The formula for obtaining the number of respondents from the three hospitals is $\left(\frac{\text { Number of beds per hospital }}{\text { Total number of beds of the } 3 \text { hospitals }}\right) \times 100$.
Thus, hospital A has 74 respondents, hospital B has 56 respondents, and hospital $\mathrm{C}$ has 35 respondents.

\section{Ethical Considerations}

Prior to the conduct of the study, approval was obtained from all the hospital administrators. Before data collection commenced, patients were approached and requested permission to complete the survey, and patients had the right to withdraw at any time. The participants were provided a cover sheet that included an explanation of the purpose of this study, directions for completing the survey, expected time to complete the survey, potential benefits and risks; privacy of participants was respected and the answers were treated confidentially.

\section{Instrumentation}

A questionnaire was the main instrument of this study. It was adapted and modified from Patient Satisfaction in Private Hospitals available in SurveyMonkey.com; the questionnaire was used because of financial constraints and it is readily available. The instrument has two parts. Part I covered the profile of the respondents: Sex, age, marital status, educational attainment, salary, the source of payment. Part II is the satisfaction survey, which is further divided into subscales; specific item answers the following: Facilities $(1,33,36,38,45)$; general service ( 3 to $18,30,31,35,37,39,40,41,42,44$ ); physician service $(19,20,21,22,23,24,27)$; nursing service $(25,26,27,28,29)$; convenience $(2,32,34,43)$; and overall satisfaction (46).

Before the conduct of the study, the researchers ran a pilot study to check the internal consistency of the instrument; the respondents for this were students and faculty members from a college in Najran who were confined in other medical facilities. Cronbach's alpha result was 0.95, which means the questionnaire has relatively high consistency and it can be used in Saudi Arabia.

\section{Tools for Data Analysis}

Statistical Package for the Social Sciences version 22 was used to analyze the data. To describe the demographic profile, frequency and percentage were used. To know the level of satisfaction of the patients, weighted mean was utilized. Table 1 summarizes the measurement of the level of satisfaction of the patients.

Table 1: Measurement of patient satisfaction

\begin{tabular}{lll}
\hline Scale & Range & Descriptive equivalent \\
\hline 5 & $4.21-5.00$ & Very satisfied \\
4 & $3.41-4.20$ & Satisfied \\
3 & $2.61-3.4$ & Neither satisfied nor dissatisfied \\
2 & $1.81-2.60$ & Dissatisfied \\
1 & $1.00-1.80$ & Very dissatisfied \\
\hline
\end{tabular}




\section{RESULTS}

Graph 1 shows that a great majority (57\%) of respondents are male, and many (43\%) are females with standard deviation $(\mathrm{SD})=0.5$. This implicates that more males are hospitalized in Najran. This may be associated with the culture of Saudi Arabia wherein it is a male-dominated country. The present finding is parallel to the findings of Mirić et al, ${ }^{8}$ wherein males are hospitalized more due to cardiovascular problems.

Graph 2 displays that almost half $(46.7 \%)$ of the respondents are 26 to 35 years old, some (30.3\%) are more than 35 years old, and few $(23 \%)$ are less than 25 years old. This finding implicates that a great majority of hospitalized patients in Najran comprise middle-age adults. This is parallel to the report of Health Research Board, ${ }^{9}$ wherein in their data, the highest admission rate is from 24 years up to 35 years.

Graph 3 shows that majority (54.5\%) of hospitalized patients are married and almost half (45.5\%) are not married. This implicates that there is a greater number of



Graph 1: Distribution of respondents according to their sex



Graph 3: Distribution of respondents according to their marital status married patients who are hospitalized; this is contrasting to the finding of Butler and Morgan ${ }^{10}$ where they found that higher rates of bed use for inpatients are used by nonmarried patients. This may be due to the changing trend in health care, and there are little to no data regarding marital status and admission.

Graph 4 shows the educational attainment of respondents, some $(35.8 \%)$ of them reached the secondary level and some $(31.5 \%)$ completed college. Few $(15.8 \%)$ of the respondents are college educated and very few $(7.9,9.1 \%)$ reached elementary and postcollege respectively. This implicates that a greater number of people hospitalized in Najran reached secondary level and college level. This is parallel to the report of General Authority for Statistic, $\mathrm{KSA}_{,}^{11}$ wherein in their data, the majority of the population in Najran reached secondary level.

Graph 5 displays the distribution of respondents according to their salary. A great majority (57.6\%) of the respondents' salary was below 5,000 SR and few (23.6\%) have a salary range of 5,001 to 8,000 SR, very few (12.1,

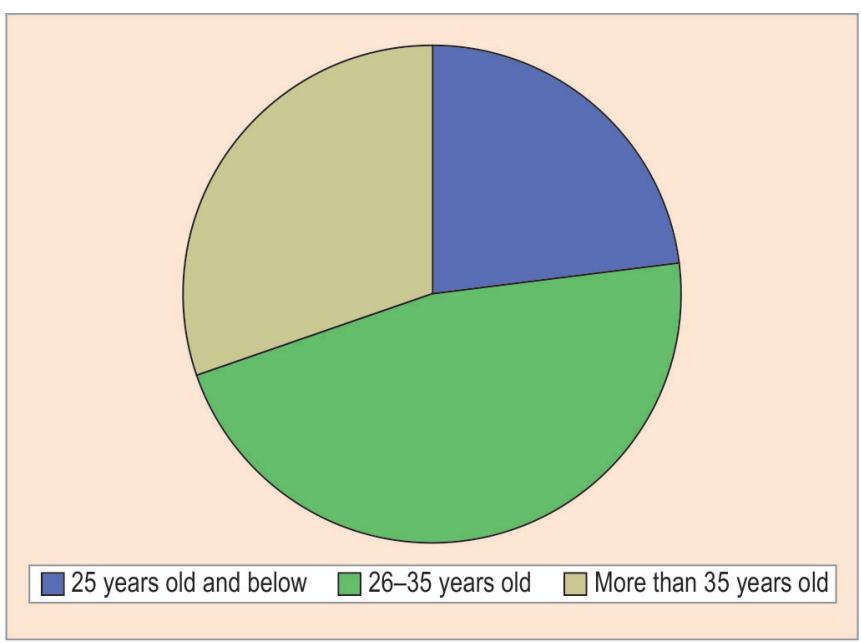

Graph 2: Distribution of respondents according to age



Graph 4: Distribution of respondents according to their educational attainment 




Graph 5: Distribution of respondents according to salary

$3.0,1.8,1.8 \%$ ) have salary range of 8,001 to $11,000,11,001$ to $14,000,14,001$ to 17,000 , and $>17,001$ SR respectively. This implicates that most of the hospitalized people in Najran belong to the minimum wage workers group. ${ }^{12}$

Graph 6 delineates that a great majority pay their hospitalization by themselves (60.6\%), and some (39.4\%) are getting payment from insurance companies. This implicates that a greater number of people hospitalized in Najran do not have health insurance. This is parallel to the study of Yan et al, ${ }^{13}$ where they found that patients without insurance have a higher risk for hospitalization.

Table 2 represents the level of satisfaction of patients for all variables. For facilities, the mean was 4.12, $\mathrm{SD}=0.85$; patients of the private tertiary hospitals are satisfied. For general services, the mean was $=4.13$, $\mathrm{SD}=0.77$; this means that patients are satisfied with what they are receiving. The physician services scored mean = $4.06, \mathrm{SD}=0.88$, also the patients were satisfied. The highest level of satisfaction according to mean is nursing services with mean $=4.22, \mathrm{SD}=0.80$, where the patients were very satisfied and the lowest among the variables is convenience with mean $=4.05, \mathrm{SD}=0.84$, but patients are still satisfied.

The overall level of patient satisfaction with the services they received indicated by the mean is $3.91, \mathrm{SD}=1.1$, this means that patients were satisfied with the services provided by the tertiary care private hospitals.

Table 2: Level of satisfaction of patients

\begin{tabular}{llll}
\hline Variables & Mean score & $S D$ & Interpretation \\
\hline Facilities & 4.12 & 0.85 & Satisfied \\
General services & 4.13 & 0.77 & Satisfied \\
Physician services & 4.06 & 0.88 & Satisfied \\
Nursing services & 4.22 & 0.80 & Very satisfied \\
Convenience & 4.05 & 0.84 & Satisfied \\
Overall & 3.91 & 1.1 & Satisfied \\
\hline
\end{tabular}



Graph 6: Distribution of respondents according to their source of payment

\section{DISCUSSION}

Private tertiary hospitals cater to male patients more than females; this may be related to health practices of males specifically linked to cigarette smoking, risk taking in recreation and driving, and employment in hazardous occupations. ${ }^{14}$ The hospitals also cater more to middle adults, because they are more susceptible to certain diseases and conditions. According to Papalia et al, ${ }^{15}$ hypertension, stress, occupational conflict, and unemployment affect the health of middle-age adults. Further, the leading causes of death during this stage are diabetes, cancer, heart disease, liver disease, and stroke. People who are married have a higher percentage of admission than those who are not married in the tertiary hospitals; this finding is contrasting to many pieces of research that say that married couples tend to be more healthier. According to Harvard Men's Health Watch, ${ }^{16}$ loneliness is another factor, i.e., linked to marriage and health; happier couples tend to be healthier. Respondents who reached secondary education account for the most number of admissions in private tertiary hospitals. Education impacts health through the development of diverse personality traits, cognitive skills, and problem-solving. ${ }^{17}$ This means that higher the education, the healthier the person is. Respondents with below 5,000 SR dominated the admission in the private tertiary hospitals; according to Archibald, ${ }^{18}$ feeling crappy about yourself can obviously lead to stress. Further, she claimed that salary is an important factor for general well-being. In terms of health insurance, there are lesser number of patients in private tertiary hospitals with a health insurance. According to Papalia et $\mathrm{al}^{15}{ }^{15}$ lack of health insurance leads to poorer health.

Nursing service garnered the highest mean score among the variables in patient satisfaction in tertiary 
hospitals in Najran, Saudi Arabia. This is very important because nurses are the front-liners in health care; they stay with patients more than the other members of the health care team, and as claimed by Needleman and Hassmiller, ${ }_{1}^{19}$ nurses have a critical role in the delivery of high-quality, efficient care that will overall affect the patient satisfaction. All other variables including the overall satisfaction garnered a satisfactory score, which is good and acceptable for tertiary hospitals.

Major limitations of this study are the lack of a causal relationship among variables by the use of a cross-sectional design; it is therefore, recommended to conduct a longitudinal study and use advanced statistics to look deeper into the relationship of variables. It is also recommended to include other tertiary hospitals in the area, especially those that are run by the government.

\section{CONCLUSION}

In light of the findings of the study, researchers conclude that patients catered to by the private tertiary hospital in Najran, Saudi Arabia, are more of males, at middle adulthood, and are married; they are educated till the secondary level, have an income of below 5,000, and have no health insurance.

The level of satisfaction of patients in the private tertiary hospital is satisfactory and that nursing service has the highest satisfaction level, which is very satisfactory.

\section{CLINICAL SIGNIFICANCE}

The findings of this study are beneficial to the success of the organization. A patient who is satisfied will spread his experience to other people. A satisfied patient will also equate to return of investment. Meeting satisfaction of patients will also decrease the risk of malpractice lawsuits.

\section{REFERENCES}

1. Nasir F, Herani G, Nawaz A. Identifying factors affecting patients' satisfaction against quality of health care services: an investigation from Aga Khan Hospital Karachi. KASBIT Business J 2012 Dec 17;5:62-68.

2. Prakash B. Patient satisfaction. J Cutan Aesthet Surg 2010 Sep;3(3):151-155.

3. Linnell P. Cost of poor service - the economic truths (n.d). CMTA world.com. Available from: http://ctmaworld.com/ economictruths.htm.

4. Virk A, Kalia M, Gupta BP, Singh J. A study to evaluate patient expectation and satisfaction in a tertiary care teaching
Hospital; 2013. Available from: http://www.iapsmgc.org/ index_pdf/133.pdf.

5. Ham HS, Peck EH, Moon HS, Yeom HA. Predictors of patient satisfaction with tertiary hospitals in Korea. Nursing Res Pract 2015;2015:749754.

6. Adekanye AO, Adefemi SA, Okuku AG, Onawola KA, Adeleke IT, James JA. Patients' satisfaction with the healthcare services at a north central Nigerian tertiary hospital. Niger J Med 2013 Jul-Sep;22(3):218-224.

7. Shekhawat S, Garg S, Jain D, Sharma U. Inpatient satisfaction level survey at a tertiary care hospital. Int J Res Med Sci 2017 Jan;5(1):240-244.

8. Mirić L, Mirić D, Duplancić D, Kokić S, Ljutić D, Pesutić V, Culić V, Fabijanić D, Titlić M. Specific and gender differences between hospitalized and out of hospital mortality due to myocardial infarction. Coll Antropol 2008 Jun;32(2):361-367.

9. Health Research Board. Hospital admissions by type of admission, age group, sex, year and statistic; 2015. Available from http://www.cso.ie/px/pxeirestat/Statire/SelectVarVal/ saveselections.asp.

10. Butler JR, Morgan M. Marital status and hospital use. Br J Prev Soc Med 1977 Sep;31(3):192-198.

11. General Authority for Statistic, KSA. Demographic Survey; 2016. Available from: https://www.stats.gov.sa/sites/ default/files/en-demographic-research-2016_4.pdf.

12. Saudi Gazette. Saudi Arabia sets minimum wage for expats at SR 2,500; 2014. Available from: http://english.alarabiya. net/en/business/economy/2014/11/12/Saudi-Arabia-setsminimum-wage-for-expats-at-SR2-500-.html.

13. Yan G, Norris KC, Greene T, Yu AJ, Ma JZ, Yu W, Cheung AK. Race/ethnicity, age, and risk of hospital admission and length of stay during the first year of maintenance hemodialysis. Clin J Am Soc Nephrol 2014 Aug 7;9(8):1402-1409.

14. Yin S. Gender disparities in health and mortality. Population Ref Bureau 2007 Nov. Available from: http://www.prb.org/ Publications/Articles/2007/genderdisparities.aspx.

15. Papalia DE, Olds SW, Feldman RD. Human development. 10th ed. McGraw-Hill Global Education Holdings, LLC; 2017. Available from: http://highered.mheducation.com/ sites/0073133809/student_view0/chapter15/index.html.

16. Harvard Men's Health Watch. Marriage and men's health. Harvard Health Publications Harvard Medical School; 2010. Available from: http://www.health.harvard.edu/ newsletter_article/marriage-and-mens-health.

17. Zimmerman EB, Woolf SH, Haley A. Understanding the relationship between education and health: a review of the evidence and an examination of community perspectives. Agency for Healthcare Research and Quality; 2015. Available from: https://www.ahrq.gov/professionals/education/ curriculum-tools/population-health/zimmerman.html.

18. Archibald A. Your job is killing you; 2013. Available from: http://www.womenshealthmag.com/health/your-job-iskilling-you.

19. Needleman J, Hassmiller S. The role of nurses in improving hospital quality and efficiency: real-world results. Health Aff (Millwood) 2009 Jul-Aug;28(4):w625-w633. 